\title{
The induction of Maspin expression by a glucosamine-derivative has an antiproliferative activity in prostate cancer cell lines
}

\author{
Rossana Cocchiola ${ }^{\mathrm{a}}$, Mariangela Lopreiato ${ }^{\mathrm{a}}$, Raffaella Guazzo ${ }^{\mathrm{b}}$, Maria Margherita de Santi ${ }^{\mathrm{b}}$, \\ Margherita Eufemi ${ }^{\mathrm{a}}$, Roberto Scandurra ${ }^{\mathrm{a}}$, Anna Scotto d'Abusco ${ }^{\mathrm{a}, *}$ \\ a Dept. of Biochemical Sciences, Sapienza University of Roma, P.le Aldo Moro, 5, 00185, Roma, Italy \\ ${ }^{\mathrm{b}}$ Division of Anatomical Pathology, Dept of Oncology, University Hospital of Siena, Via delle Scotte, 6, 53100, Siena, Italy
}

\section{A R T I C L E I N F O}

\section{Keywords:}

Maspin

Prostate cancer

Glucosamine-derivative

Therapeutic strategies

\begin{abstract}
A B S T R A C T
Mammary serine protease inhibitor or Maspin has been characterized as a class II tumor suppressor gene in several cancer types, among them prostate cancer (CaP). Androgen ablation is an effective therapy for CaP, but with short-term effectiveness, thus new therapeutic strategies are actively sought. The present study is aimed to explore the effects of a glucosamine derivative, 2 -(N-Carbobenzyloxy)L-phenylalanylamido-2-deoxy- $\beta$-D-glucose (NCPA), on two CaP cell lines, PC3 and LNCaP.

In particular we analyzed the impact of NCPA on Maspin production, cell viability and cell cycle progression and apoptosis/necrosis pathway activation in PC3 and LNCaP cell lines.

NCPA is able to stimulate Maspin production in PC3 and not in LNCaP cell lines. NCPA blocks the PC3 cell cycle in G1 phase, by inhibiting Cyclin D1 production and induces the apoptosis, therefore interfering with aggressiveness of this androgen-insensitive cell line. Moreover, NCPA is able to induce the expression of Maspin in LNCaP cell line treated with androgen receptor inhibitor, Bicalutamide, and in turn to stimulate the apoptosis of these cells.

These findings suggest that NCPA, stimulating the endogenous production of a tumor suppressor protein, could be useful in the design of new therapeutic strategies for treatment of CaP.
\end{abstract}

\section{Introduction}

Prostate Cancer ( $\mathrm{CaP}$ ) is the most common form of male tumor and is the second leading cause of cancer death. The disease progresses from intra-epithelial neoplasia to locally invasive adenocarcinoma, and then to hormone-refractory metastatic carcinoma [1]. Androgen ablation has proved to be an effective therapy for metastatic prostate cancer, but the regression of metastatic lesions lasts only 18-24 months [2]. The majority of men becomes refractory to androgen blockade, with a median survival time of 9-12 months. In addition to androgen receptor (AR) signaling, it has become evident that other signaling pathways are involved in prostate cancer development and progression [3].

Oncogenic processes, such as mutation of Ras and activation of $\mathrm{Bcl} 2$, or loss of function by tumor suppressor genes also contribute to tumor progression. Maspin (Mammary Serine Protease Inhibitor or SerpinB5) is a tumor-suppressing serine protease inhibitor initially isolated from normal human mammary epithelial cells. Maspin is a $42 \mathrm{kDa}$ protein and is an unusual member of Serpin superfamily, which includes inhibitory members that target proteases, as well as non-inhibitory members that possess a diverse array of functions [4].

Functional studies have demonstrated that Maspin inhibits tumor invasion and motility of human mammary tumor cells in cell culture models [5], as well as tumor growth and metastasis in the nude mice assay [6]. The overexpression of Maspin is a predicting favorable prognosis factor in breast cancer and in lung squamous cell carcinoma $[7,8]$. However, the exact role of Maspin in tumors is still controversial since conflicting experimental and clinical results are reported. Although the significance of Maspin expression varies in different tumors, the expression of Maspin is frequently absent in prostate cancer [9]. In the prostate, expression of Maspin is regulated by both positive and negative mechanisms at the transcriptional level. It has been identified the Ets site as a positive regulator of Maspin expression, and the hormone responsive element (HRE) sites that bind the androgen receptor as cis elements involved in negatively regulated Maspin transcription

\footnotetext{
* Corresponding author. Department of Biochemical Sciences, Sapienza University of Roma, P.le A. Moro, 5, 00185, Roma, Italy.

E-mail addresses: rossana.cocchiola@uniroma1.it (R. Cocchiola), mariangela.lopreiato@uniroma1.it (M. Lopreiato), raffaellaguazzo@tiscali.it (R. Guazzo), desantim@ao-siena.toscana.it (M.M. de Santi), margherita.eufemi@uniroma1.it (M. Eufemi), roberto.scandurra@uniroma1.it (R. Scandurra), anna.scottodabusco@uniroma1.it (A. Scotto d'Abusco).
} 

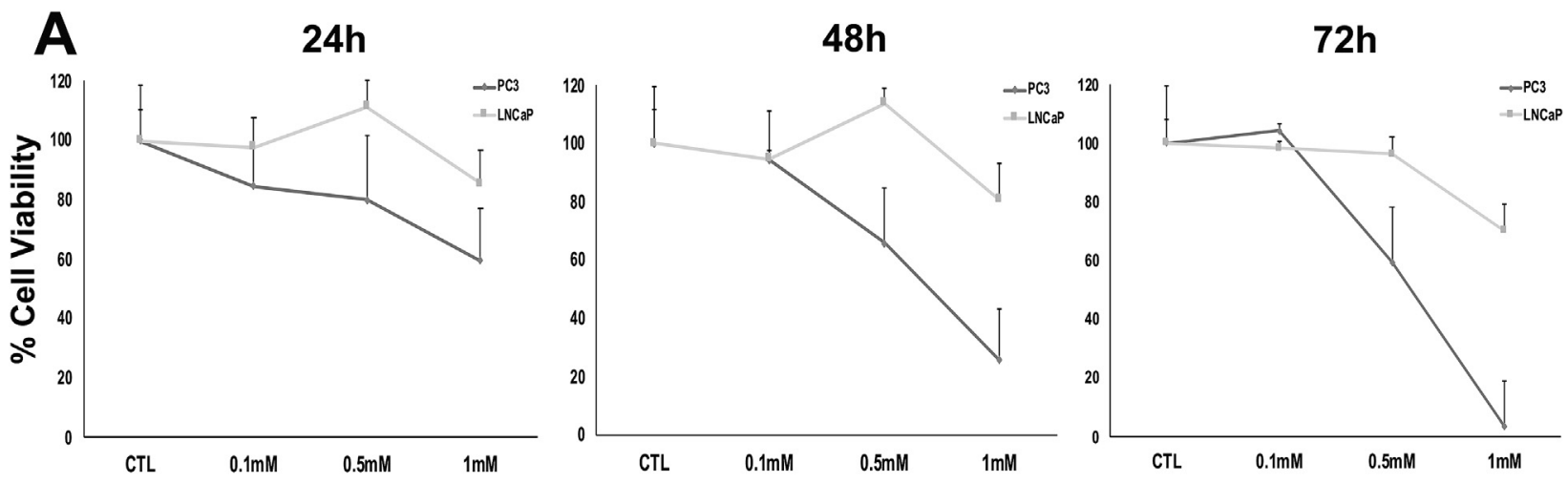

B
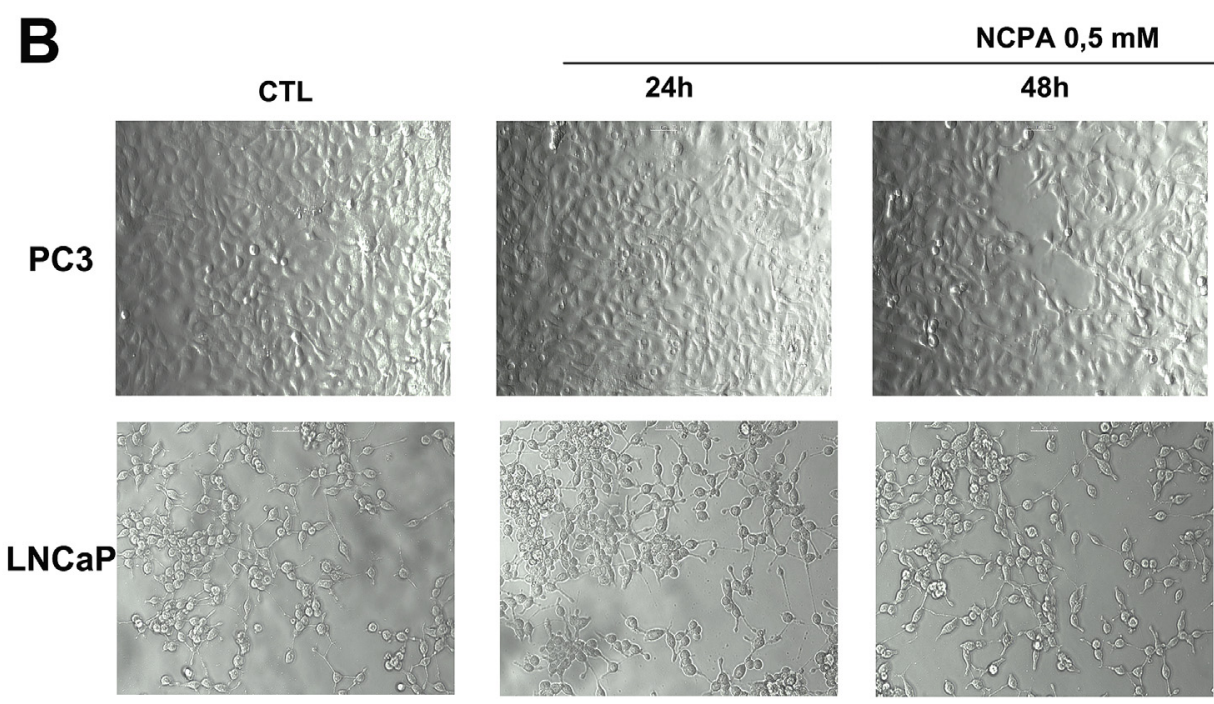

NCPA $0,5 \mathrm{mM}$
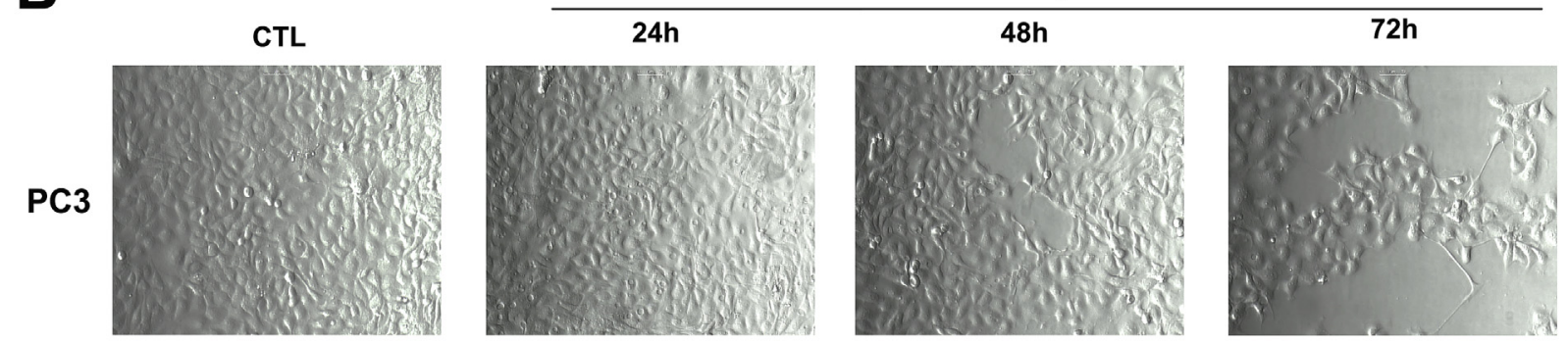

Fig. 1. Effect of NCPA on cell viability. A: Cell viability was assessed by MTS (3-[4,5-dimethylthiazol-2-yl]-5-[3-carboxymethoxyphenyl]-2-[4-sulfophenyl]-2Htetrazolium) based colorimetric assay. Cells were left untreated (CTL) or treated with 0.1, 0.5 and $1 \mathrm{mM} \mathrm{NCPA}$, for $24 \mathrm{~h}, 48 \mathrm{~h}$ and $72 \mathrm{~h}$; B: Representative image of cells untreated (CTL) or treated with $0.5 \mathrm{mM} \mathrm{NCPA}$ for $24 \mathrm{~h}, 48 \mathrm{~h}$ and $72 \mathrm{~h}$. Experiments were repeated at least three times. Photographs were taken with Leica DM IL LED using AF6000 modular Miscroscope (original magnification 20x).

[10].

In the androgen-sensitive LNCaP cells, androgen receptor can recognize and bind to the androgen responsive element (ARE), and then inhibits the activity of Maspin promoter. Androgen down-regulates Maspin expression and the androgen ablation induces Maspin gene expression in LNCaP cells [11]. Maspin expression that correlates with good prognosis, may serve as a biomarker for prostate cancer cells responding to androgenic ablation therapy [11]. The repressive function of ARE of the Maspin promoter is inactive in androgen-insensitive PC3 cells; in these cells, the protein RelB could be a modulator that bypasses the normal expression control of Maspin production [9]. Moreover, the repression of translocation into the nucleus of IKK $\alpha$, a crucial upstream molecule in both classical and alternative NF- $\mathrm{KB}$ signaling pathway $[12,13]$, has been associated with repression of the metastatic phenotype. Luo et al. [14] demonstrated that the nuclear localized IKK $\alpha$ interacts with the Maspin promoter and causes transient repression of Maspin expression in prostate cancer.

In the last years, in our laboratory, we studied the effects on inflammatory pathways of some peptidyl-derivatives of glucosamine [15], a natural aminosugar present in extracellular matrix glycosaminoglycans. We found that some of these glucosamine derivatives, i.e. 2(N-Acetyl)-L-phenylalanylamido-2-deoxy- $\beta$-D-glucose (NAPA) and 2-(NCarbobenzyloxy)L-phenylalanylamido-2-deoxy- $\beta$-D-glucose (NCPA), were able to inhibit the migration into the nucleus of IKKa and NAPA was also able to partially inhibit IKK $\alpha$ kinase activity [16]. Taking into account the role of nuclear IKKa in cancer progression through repression of Maspin expression, we investigated whether these molecules were able to stimulate the Maspin expression by inhibiting IKK $\alpha$ nuclear migration in 143B osteosarcoma cells, demonstrating that NCPA was strongly able to interfere with this event [17]. Considering the role of Maspin in prostate cancer, we decided to test whether NCPA was able to stimulate the production of Maspin in two different prostate carcinoma cell lines, androgen-insensitive PC3 and androgen-sensitive LNCaP.

\section{Material and methods}

\subsection{Cell culture}

Human prostate carcinoma cell lines PC3 and LNCaP, obtained from the American Type Culture Collection (ATCC, Rockville, MD, USA), were used. Cells were cultured in RPMI 1640 (Sigma Aldrich, St. Louis, MO, USA) supplemented with $10 \%$ fetal bovine serum (FBS), L-glutamine, $1 \%$ sodium pyruvate, $100 \mathrm{U} / \mathrm{mL}$ of penicillin (final concentration), and $100 \mu \mathrm{g} / \mathrm{mL}$ of streptomycin (final concentration) (penicillin/ streptomycin, Sigma Aldrich). Both cell lines were cultured at $37^{\circ} \mathrm{C}$ and $5 \% \mathrm{CO}_{2}$ according to ATCC recommendations. Experiments were performed using $80 \%$ confluent monolayer cells.

\subsection{Cell treatment}

Cells were left untreated (CTL) or treated with $0.5 \mathrm{mM} \mathrm{2-(N-}$ 
PC3
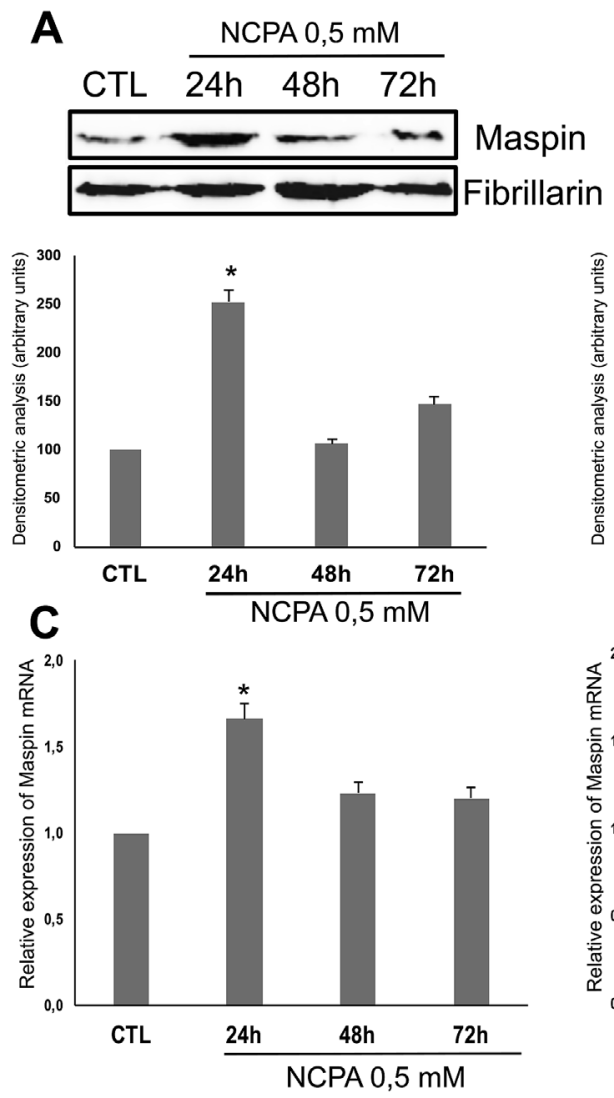

LNCaP
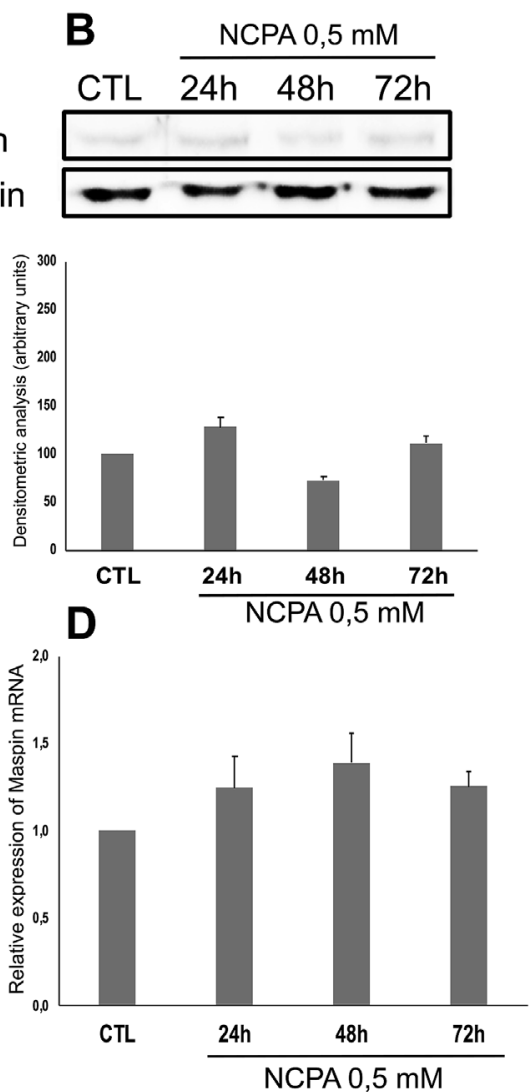

Fig. 2. NCPA enhances Maspin production in PC3 cells. A: Proteins from PC3 cells, untreated (CTL) or treated with $0.5 \mathrm{mM}$ NCPA for $24 \mathrm{~h}, 48 \mathrm{~h}$ and $72 \mathrm{~h}$, were extracted and nuclear extract was analyzed by Western blot, using antiMaspin antibody and anti-Fibrillarin as loading control. Bar graph represents the densitometric analysis of positive bands normalized using the amount of fibrillarin; B: LNCaP cells were treated, extracted and analyzed as described in A; C: PC3 cells and D: LNCaP cells, treated as described in A, were harvested and mRNA was extracted and analyzed by RT-PCR. Data are expressed as mRNA level calculated by $2^{-\Delta \Delta \mathrm{Ct}}$ method with respect to GAPDH mRNA. Results represent the mean \pm S.E.M. of data obtained by three independent experiments. Statistical significance was: ${ }^{*} \mathrm{p}<0.05$.
Carbobenzyloxy)-L- phenylalanylamido-2-deoxy- $\beta$-D-glucose (NCPA), molecule synthesized in our laboratory [15], for the required time. To inhibit the androgen receptor, cells were pretreated ON with $120 \mu \mathrm{M}$ Bicalutamide (Sigma Aldrich) and then treated with $0.5 \mathrm{mM}$ NCPA plus $40 \mu \mathrm{M}$ Bicalutamide, for the required time.

Experiments were independently repeated at least three times.

\subsection{Cell viability}

To detect potential cytotoxic effects of NCPA at concentrations and times used, the survival of the cells treated with this molecule was evaluated using MTS (3-[4,5-dimethylthiazol-2-yl]-5-[3-carboxymethoxyphenyl]-2-[4-sulfophenyl]-2H-tetrazolium) based colorimetric assay (Promega Corporation, Madison, WI, USA), according to the manufacturer's instructions. Briefly, $1 \times 10^{3}$ PC3 cells and $3 \times 10^{3}$ LNCaP cells per well, according to growth rate, were seeded in a 96well plate. MTS was added to the well containing untreated and treated cells, $24 \mathrm{~h}, 48 \mathrm{~h}$ and $72 \mathrm{~h}$ after treatment. Spectrophotometric absorbance was measured at $492 \mathrm{~nm}$.

Cells were observed at $24 \mathrm{~h}, 48 \mathrm{~h}$ and $72 \mathrm{~h}$ under optical microscope, by Leica DM IL LED using AF6000 modular Microscope.

\subsection{RNA extraction and reverse-transcription}

Total RNA was extracted with TRIZOL (Invitrogen, Thermo Fisher Scientific), purified using micro RNeasy column (Qiagen, Valencia, CA, USA) and reverse transcribed by TetroReverse transcriptase enzyme, (Bioline, London, UK), according to the manufacturers' instructions.

\subsection{Quantitative-Real Time-PCR}

Quantitative-Real Time-PCR analysis was performed using an ABI
Prism 7300 (Applied Biosystems, Thermo Fisher Scientific). Amplification was carried out using SensimixPlus SYBR Master mix (Bioline). Primers were designed using Primer Express software (Applied Biosystems) and were synthesized by Biofab Research (Rome, Italy), Maspin (NM_002639) forward: 5'-GCCAGGAGCACGGATCCT-3' and reverse: 5'-GTTGTGCCTGATGATGTAAATAAAGG-3', GAPDH (NM_002046) forward: 5'-GGAGTCAACGGATTTGGTCGTA-3' and reverse: 5'-GGCAACAATATCCACTTTACCAGAGT-3'.

Relative expression levels were normalized with glyceraldheyde-3phosphate dehydrogenase (GAPDH) as housekeeping gene. Data were analyzed by $2^{-\Delta \Delta \mathrm{Ct}}$ method [18] and expressed as fold change compared to CTL.

\subsection{Western blotting}

To analyze the effect of NCPA on Maspin protein expression, we performed western blot experiments. Cells, untreated and treated as above described, were washed with phosphate buffer saline (PBS) and lysated by nuclear extract kit (Active Motif, Carlsbad, CA, USA) to separate the cytosolic from nuclear extract in accordance with manufacturer's instructions. Extracts were resolved on Mini-protean TGX precast gels (Bio-Rad Laboratories, Hercules, CA, USA) and transferred to PVDF membranes (Bio-Rad) and probed with specific antibody, in accordance with the manufacturer's instructions. Antibody anti-Maspin was from BD Pharmingen (BD Biosciences, San Jose, CA, USA).

\subsection{Immunocytochemistry}

Immunostaining was performed by an automated staining system (Ventana BenchMark ULTRA, Roche diagnostic, Monza-Italy) in accordance with the manufacturer's instructions. Antigen epitopes were retrieved using Ventana Benchmark CC1 standard program. The 

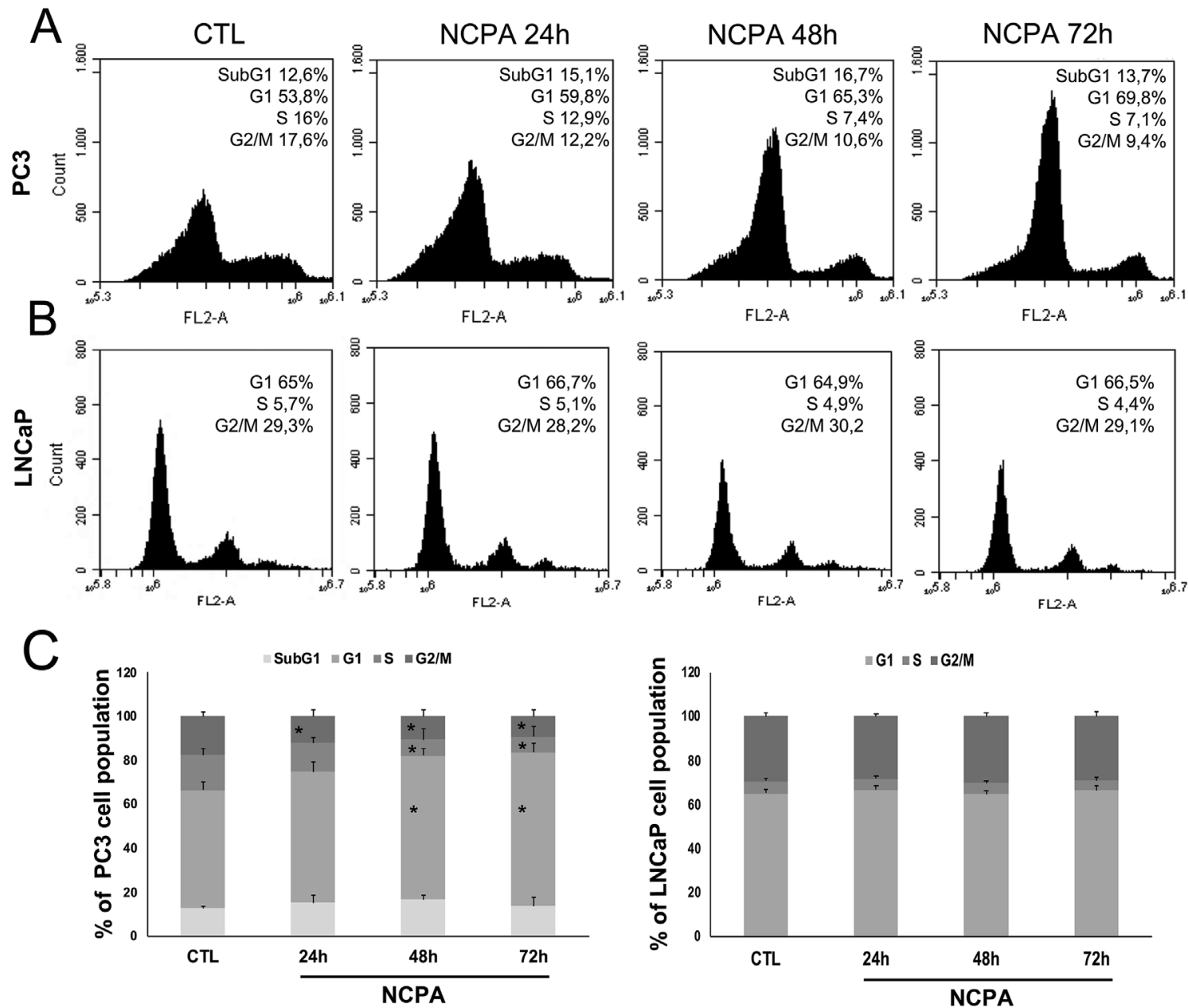

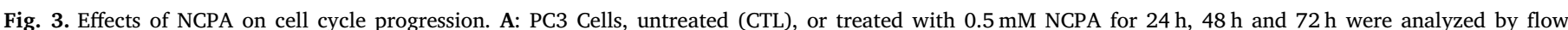

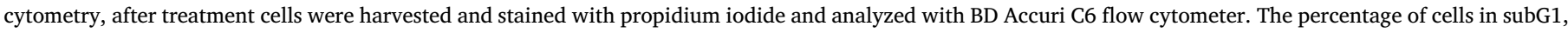

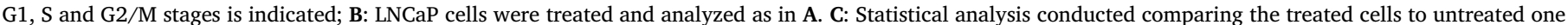
$(*=\mathrm{p}<0.05)$.

antibody anti-cyclin D1 (rabbit monoclonal clone SP4-R; Ventana Medical Systems, Inc.) was incubated for $32 \mathrm{~min}$ and $60 \mathrm{~min}$ at $37^{\circ} \mathrm{C}$. The slides were counterstained with hematoxylin, mounted and analyzed with Leica LAS V3.8 Software (Leica Microsystems, Switzerland) associated with the Leica DMRB microscope.

\subsection{Fluorescence in situ hybridization (FISH)}

FISH analysis for CCND1 (Cyclin D1) gene copy number was performed using SPEC CCND1/CEN 11 Dual Color Probe ZytoLight (BioOptica, Germany), CCND1 gene was labeled with green fluorophore, and CEN11 (centromere) was labeled with orange fluorophore, following the manufacturer's protocol.

For each specimen, at last 100 intact non-overlapping cells with good signals were analyzed. FISH images were acquired at $63 \mathrm{x}$ magnification utilizing Leica DM 6000B fluorescence microscope (Leica Microsystems, Switzerland) equipped with DAPI, SpectrumGreen ${ }^{\mathrm{TM}}$, SpectrumOrange ${ }^{\mathrm{TM}}$ filters. Images were processed by Leica LAS V3.8 Software (Leica Microsystems, Switzerland) to obtain a quantitative analysis of genes.

\subsection{Transmission electron microscopy (TEM)}

After treatment, cells were immediately fixed in $2.5 \%$ cacodylate buffered glutaraldehyde, $\mathrm{pH} 7.3$, for $2 \mathrm{~h}$ at $4{ }^{\circ} \mathrm{C}$ and pelleted by centrifugation at $1200 \mathrm{rpm}$ for $5^{\prime}$ at RT. Samples were washed overnight in the same buffer, post-fixed in buffered $1 \%$ osmium tetroxide for $1 \mathrm{~h}$, dehydrated through a graded series of acetone and embedded in Epoxy resin (Araldite, Fluka). Semithin sections $(1 \mu \mathrm{m})$, were cut with a glass knive on Leica EM UC7 Ultratome, stained with toluidine blue and examined by light microscope for a general evaluation of cells morphology. Ultrathin sections were cut with a diamond knife (Diatome) at 60-80 nm, retrieved onto copper grids, double-stained with Uranyl Acetate Replacement Stain (UAR-EMS) and lead citrate and examined at $100 \mathrm{kV}$ with a Philips EM208 S electron microscope.

\subsection{Flow cytometry}

In order to analyze cell cultures by flow cytometry, the cells were harvested from dishes by digesting with trypsin. Then the cells were pelleted, at $800 \mathrm{~g}$ for $10 \mathrm{~min}$ at $25^{\circ} \mathrm{C}$ resuspended in PBS and fixed in PBS plus $70 \%$ ethanol for $10 \mathrm{~min}$ at $4{ }^{\circ} \mathrm{C}$. After washing cells were incubated with RNase A $(50 \mu \mathrm{g} / \mathrm{mL})$ for $30 \mathrm{~min}$ at $37^{\circ} \mathrm{C}$, sequentially stained with propidium iodide $(100 \mu \mathrm{g} / \mathrm{mL})$ for $1 \mathrm{~h}$ and analyzed by BD Accuri C6 flow cytometer (BD Bioscience, Milano, Italy), to evaluate the cell cycle progression.

The apoptosis/necrosis assay was performed using Annexin V-FITC kits (Immunological Sciences), according to the manufacturer's instructions. 

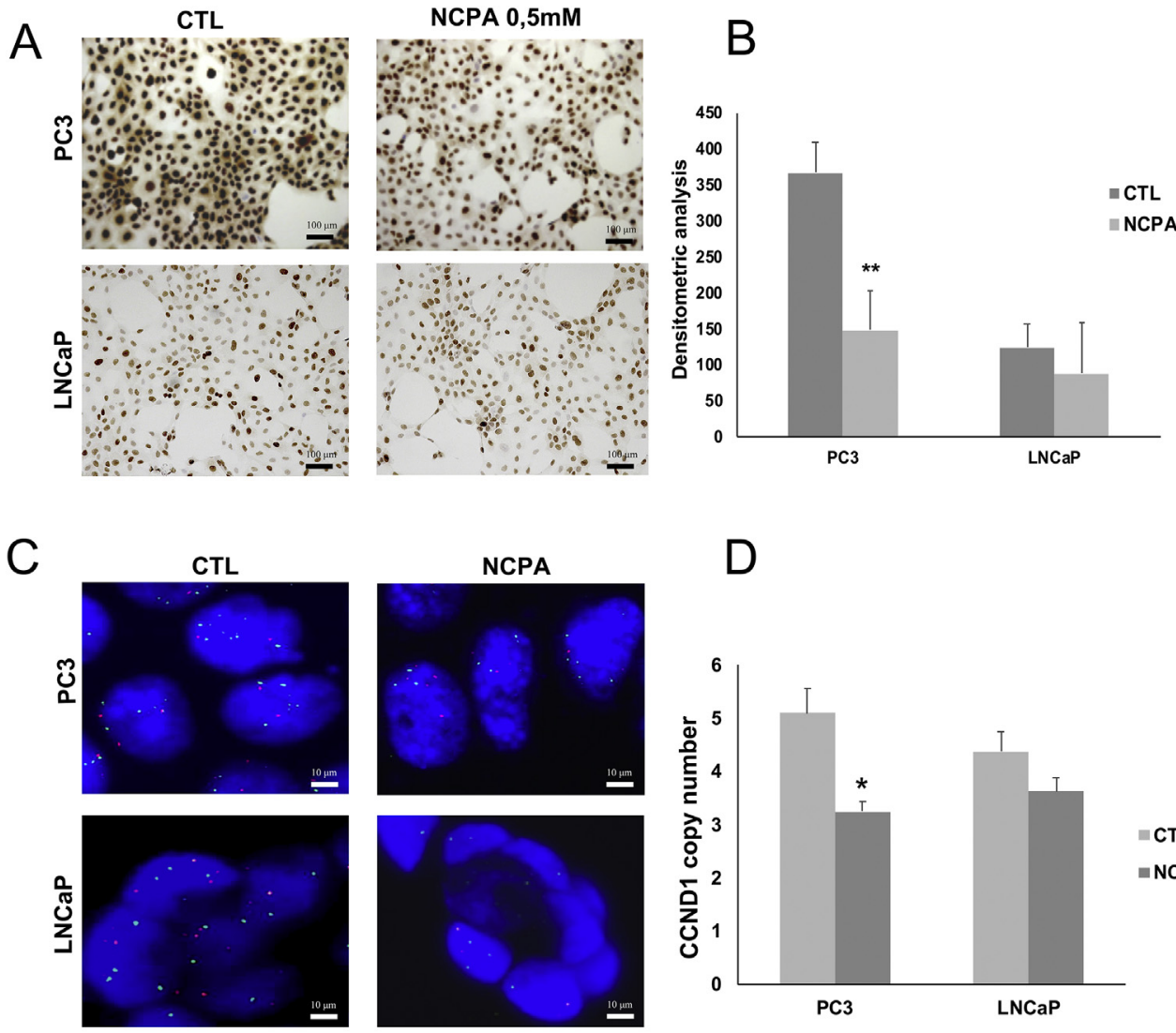

$\mathrm{E}$
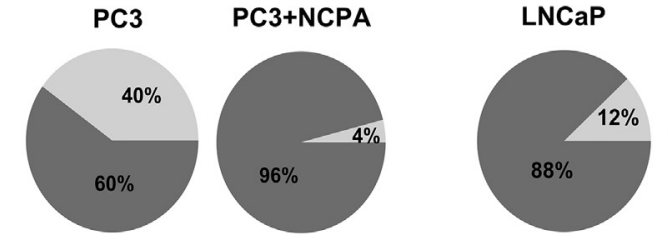

LNCaP+NCPA

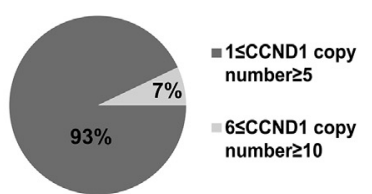

Fig. 4. NCPA affects Cyclin D1 production and CCND1 gene amplification. A: PC3 and LNCaP cells untreated (CTL), or treated with $0.5 \mathrm{mM}$ NCPA for $48 \mathrm{~h}$ were analyzed by immunocytochemistry using anti-Cyclin D1 rabbit monoclonal antibody (original magnification 20x, scale bar $=100 \mu \mathrm{m})$. B: Bar graph representing the densitometric analysis of positive nuclei in PC3 and LNCaP cells, analyzed by ImageJ software; C: PC3 and LNCaP cells, treated as described in A, were analyzed by FISH using SPEC CCND1/CEN 11 Dual Color Probe ZytoLight, CCND1 labeled with green fluorophore the cyclin D1 gene; CEN11 labeled the centromeres with orange fluorophore (representative image, original magnification $63 \mathrm{x}$, scale bar $=10 \mu \mathrm{m})$. $\mathbf{D}$ : Bar graph representing the CCND1 copy number average in both cell lines; E: Graphic representation of low-level CCND1 gene amplification (light grey) or non-amplified (dark grey) in PC3 and LNCaP cell lines.

\subsection{Statistics}

All data were obtained from at least three independent experiments, each performed either in duplicate or in triplicate. Data were statistically analyzed with two-way repeated measures analysis of variance (ANOVA) with Bonferroni's multiple comparison test, using Prism 5.0 software (GraphPad Software, San Diego, CA, USA). P value $<0.05$ was considered significant.

\section{Results}

\subsection{Effect of NCPA on cell viability}

To determine the dose-response and the time-course effect of NCPA on cell viability, PC3 and LNCaP cells were exposed to $0.1,0.5$, and $1 \mathrm{mM}$ NCPA for $24 \mathrm{~h}, 48 \mathrm{~h}$ and $72 \mathrm{~h}$. Cell viability was measured by MTS method. NCPA significantly inhibited PC3 cell viability at $1 \mathrm{mM}$ concentration at all time points; it showed a slight detrimental effect at $0.5 \mathrm{mM}$ at $24 \mathrm{~h}$ and $48 \mathrm{~h}$, and a major detrimental effect at $72 \mathrm{~h}$; finally, it resulted ineffective at $0.1 \mathrm{mM}$ concentration at any time point (Fig. 1A). NCPA did not affect LNCaP cell viability at any time point and concentration used (Fig. 1A). PC3 cells treated with $0.5 \mathrm{mM}$ NCPA and observed under optical microscope, showed a cell number decrease, whereas treated LNCaP showed the same cell number of the untreated ones (Fig. 1B). For further analyses, we decided to use $0.5 \mathrm{mM}$ concentration, which is the concentration that induced $50 \%$ reduction in cell viability in PC3 after $72 \mathrm{~h}$ treatment and it is also the same concentration used in our previous publication on osteosarcoma cell line [17].

\subsection{Effect of NCPA on maspin production}

To determine the effect of NCPA on Maspin production and Maspin sub-cellular localization in PC3 and LNCaP, we analyzed those cell lines treated with $0.5 \mathrm{mM}$ NCPA at different times by western blot. Nuclear extract from NCPA-treated samples showed a statistically significant increase of Maspin production after $24 \mathrm{~h}$ treatment ( $\mathrm{p}<0.05$ ), which returned back to control level after $48 \mathrm{~h}$ and $72 \mathrm{~h}$ treatment, in PC3 cell line (Fig. 2A). NCPA did not stimulate Maspin production in LNCaP cell line at any time point (Fig. 2B).

The increase in Maspin protein level in PC3 was concurrent with the transcriptional up-regulation, which was statistically significant after $24 \mathrm{~h}$ treatment (*p $<0.05)$ and was not statistically significant after $48 \mathrm{~h}$ and $72 \mathrm{~h}$ (Fig. 2C). According to protein expression, in LNCaP cells, NCPA was not able to affect Maspin mRNA expression level (Fig. 2D).

\subsection{Effect of NCPA on cell cycle progression and cell proliferation}

The tumor suppressor molecule Maspin has been described to be involved in several cell activities such as tumor cell motility, invasion, metastasis and apoptosis. Considering that NCPA was able to stimulate the Maspin production in PC3 and not in LNCaP cell line, we evaluated the effect of this molecule on cell cycle progression in both cell lines by 


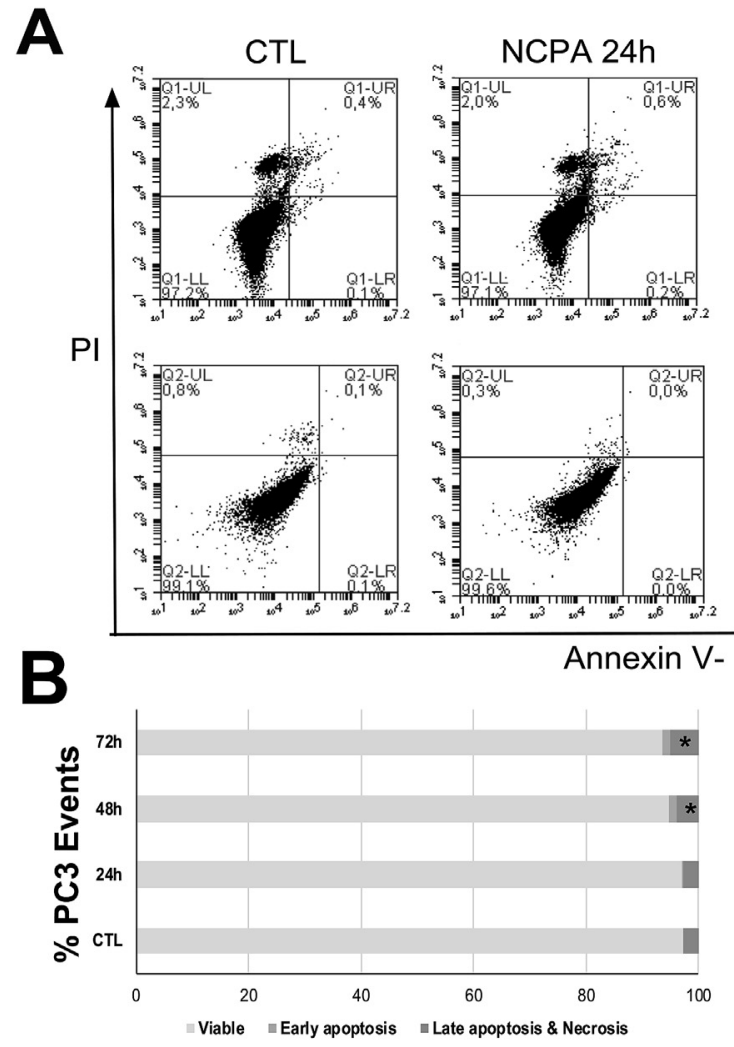

C
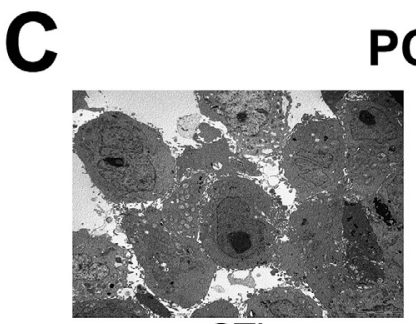

CTL

PC3

NCPA
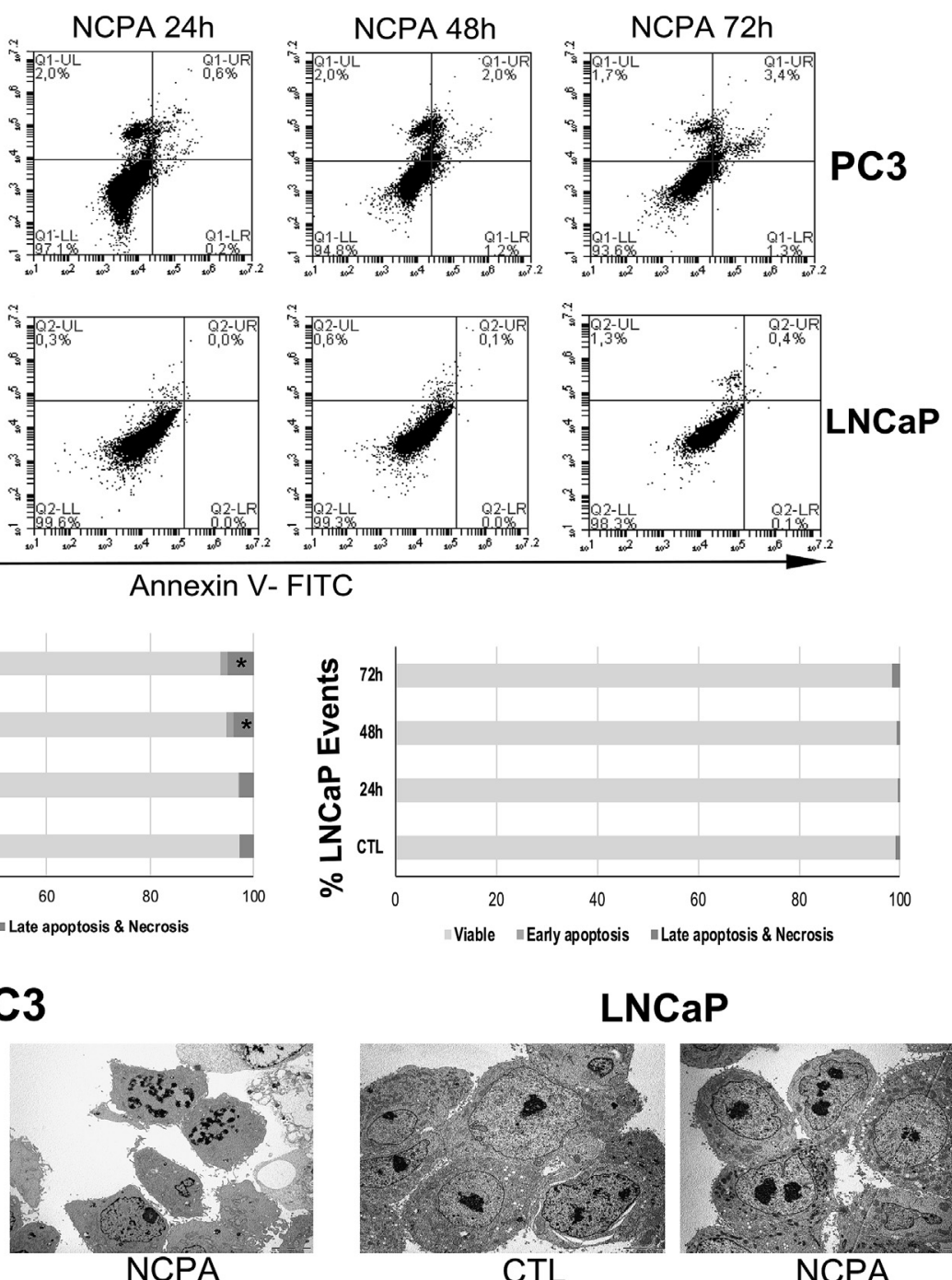

\section{LNCaP}

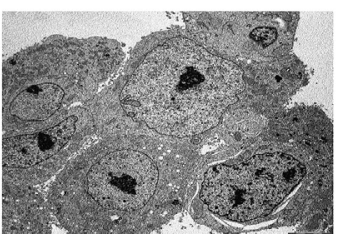

CTL

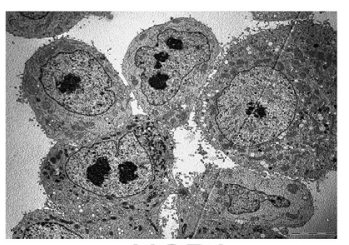

NCPA

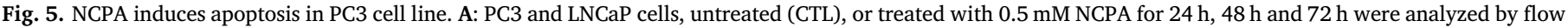

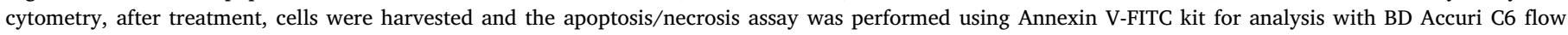

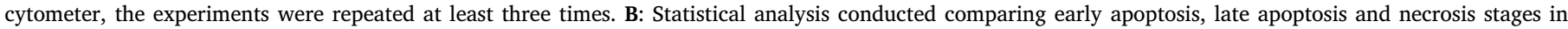

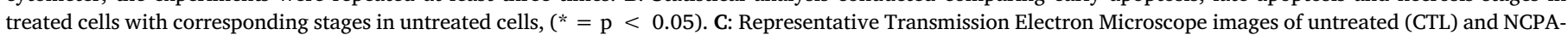
treated PC3 and LNCaP cells $(0.5 \mathrm{mM}$ for $72 \mathrm{~h}$ ) (scale bar $=5 \mu \mathrm{m})$.

flow cytometry.

The percentage of NCPA-treated PC3 cells in subG1 (G0/G1) stage increased progressively at $24 \mathrm{~h}(15.1 \%), 48 \mathrm{~h}(16.7 \%)$ and remained stable at $72 \mathrm{~h}(13.7 \%)$, whereas the percentage in G1 increased at all analyzed times, at $24 \mathrm{~h}(59.8 \%), 48 \mathrm{~h}(65.3 \%, \mathrm{p}<0.05)$ and mainly at $72 \mathrm{~h}(69.8 \%, \mathrm{p}<0.05)$, alongside, percentage of cells in S $12.9 \%$ at $24 \mathrm{~h}, 7.4 \%$ at $48 \mathrm{~h}$ and $7.1 \%$ at $72 \mathrm{~h}, \mathrm{p}<0.05$ for all time point analyzed) and G2/M (12.2\% at $24 \mathrm{~h}, 10.6 \%$ at $48 \mathrm{~h}$ and $9.4 \%$ at $72 \mathrm{~h}$, $\mathrm{p}<0.05$ for $48 \mathrm{~h}$ and $72 \mathrm{~h}$ ) stages decreased (Fig. 3A). The percentage of LNCaP cells was almost the same in untreated and treated samples at every time point, with no detectable subG1 (G0/G1) cells (Fig. 3B). The statistical analysis was performed comparing treated cells to untreated one (Fig. 3C).

\subsection{Effect of NCPA on cyclin D1 (CCND1) gene amplification}

Considering that Cyclin D1 protein is one of the major regulator of the progression of cell cycle, we analyzed, by immunocytochemistry, the presence of this protein in untreated and treated cells, finding that Cyclin D1 was present in large amount in untreated PC3 cell nuclei, and was significantly decreased in NCPA-treated PC3 cell nuclei (Fig. 4A and B). According to the cell cycle analysis, LNCaP showed very low amount of Cyclin D1 levels in untreated and treated cells, respectively (Fig. 4A and B).

Cyclin D1 protein overexpression has been shown to be significantly associated to high CCND1 gene amplification, for this reason we analyzed the CCND1 amplification by FISH [19]. Kim et al. defined "gene amplification" as > 6 gene copies per nucleus in gastric cancer [20] and Turner et al. found 4-10 CCND1 gene copies per nucleus in PC3 cell line [21]. We analyzed CCND1 gene copy number in 100 nuclei both in untreated and treated PC3 cells or LNCaP cells. A representative image of all analyzed samples is reported (Fig. 4C). Comparing the average of CCND1 gene amplification in both cell lines, we observed that CCND1 average is significantly decreased in PC3 treated cells, whereas CCND1 average was unchanged in LNCaP treated cells compared to untreated ones (Fig. 4D). Amplification of CCND1 gene was detected in $40 \%$ of PC3 untreated cells, while in NCPA-treated cells only in 4\% of cells. Conversely, in LNCaP untreated cells, amplification of CCND1 was observed in $12 \%$ of cells, while in NCPA-treated cells was observed in $7 \%$ of cells (Fig. 4E). 

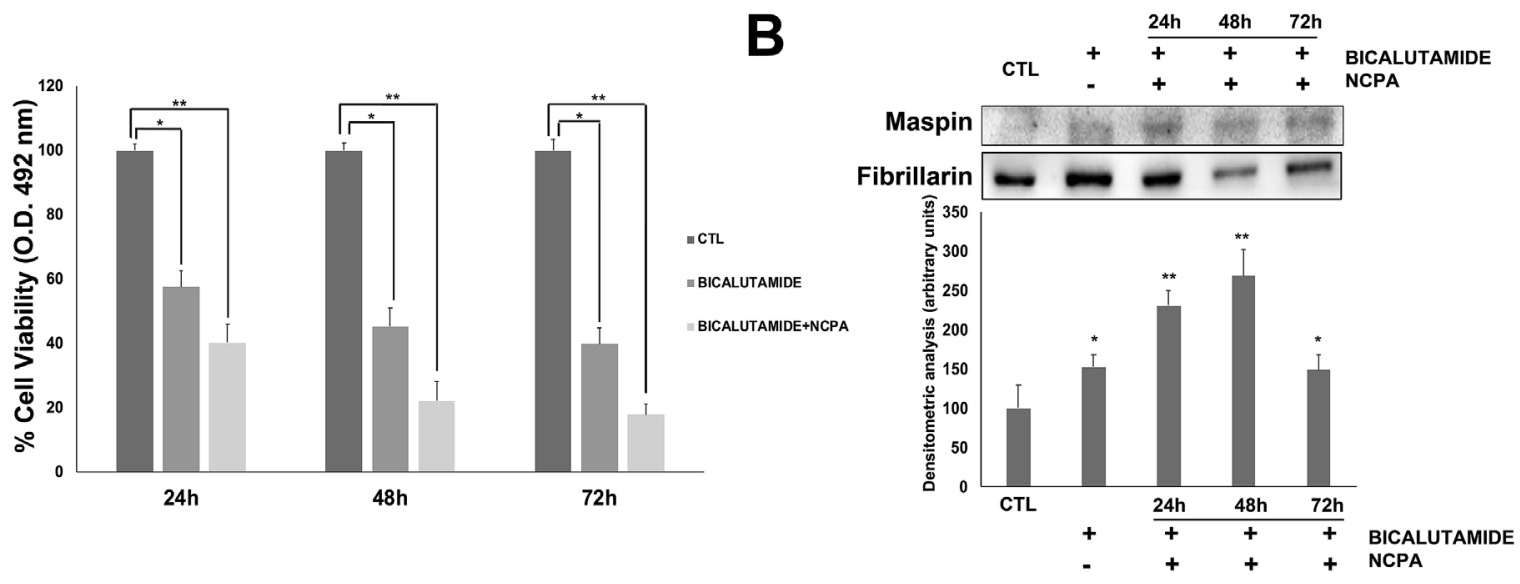

C
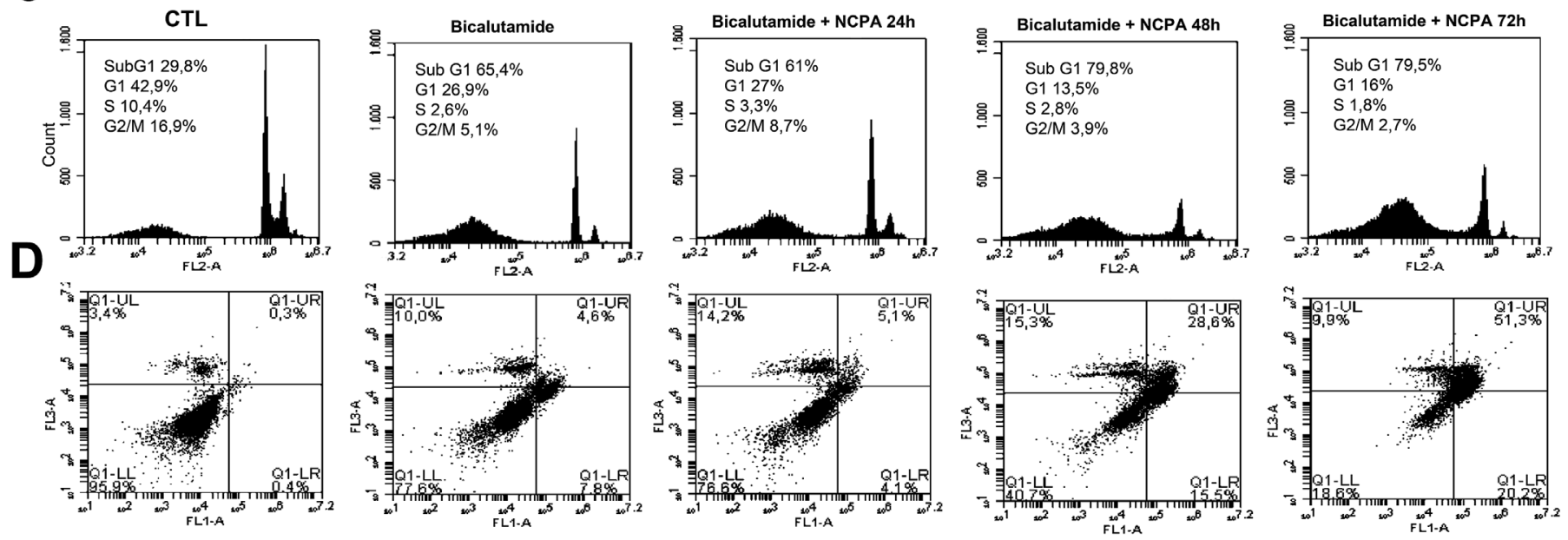

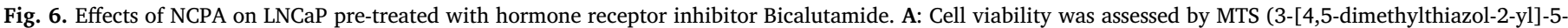

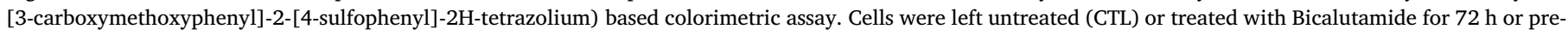

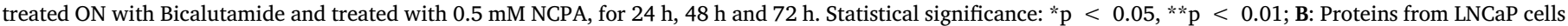

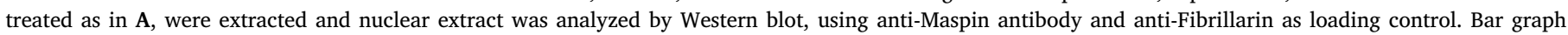

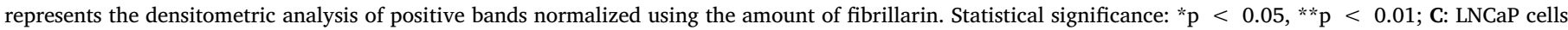

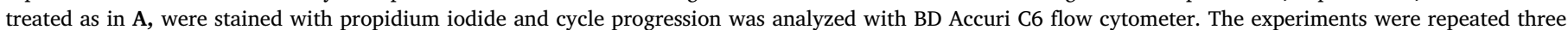

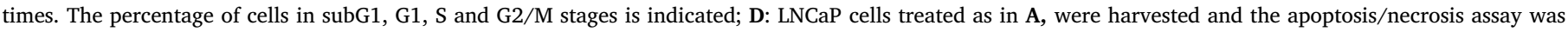

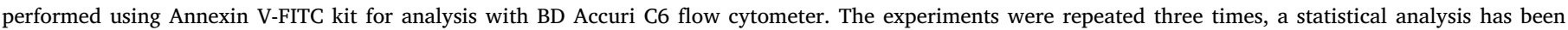

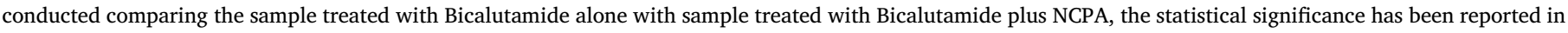
Results section.

\subsection{Effect of NCPA on apoptosis in PC3}

To verify the ability of NCPA to induce apoptosis, an apoptosis/ necrosis assay was performed by flow cytometry, revealing that NCPA treatment induced apoptosis, both after $48 \mathrm{~h}$ and mainly after $72 \mathrm{~h}$. The percentage of early apoptosis was $1.2 \%$ and $1.3 \%$ after $48 \mathrm{~h}$ and $72 \mathrm{~h}$ respectively, and late apoptosis $2.0 \%$ and $3.4 \%$ after $48 \mathrm{~h}$ and $72 \mathrm{~h}$, respectively, whereas, it was $0.1 \%$ early and $0.4 \%$ late apoptosis in untreated cells. As observed in Fig. 5B, compared to the untreated cells, a statistically significant increase in the ratio of apoptosis cells was observed in $48 \mathrm{~h}$ and $72 \mathrm{~h}$ treated cells. LNCaP cells did not show any apoptosis feature at any time point in accordance with cell cycle analysis (Fig. 5A).

To further demonstrate that cell death monitored by flow cytometry was due to apoptosis we analyzed cells by TEM and we observed apoptotic nuclei in NCPA-treated PC3 cells, whereas apoptotic nuclei were not observed in LNCaP neither in untreated nor in treated cells (Fig. 5B).

\subsection{Effect of NCPA on LNCaP cells treated with AR inhibitor}

In order to confirm that the stimulation of Maspin production in PC3 cell line was directly involved in the induction of apoptosis and consequently in cell death, we analyzed if the stimulation of Maspin production in LNCaP could induce the same effects. LNCaP are hormonesensible cells and in the promoter region of Maspin, a Hormone Responsive Element that negatively controls the Maspin production is present [10]. We treated the LNCaP cells with Bicalutamide, an Androgen Receptor (AR) inhibitor and then with NCPA, finding that it induced a statistically significant cell death compared to untreated cells, but the co-treatment with NCPA further induced cell death significantly higher than Bicalutamide alone, with the highest effect after $72 \mathrm{~h}$ (Fig. 6A). In order to verify if the treatment with Bicalutamide could induce the production of Maspin, we performed a western blot experiment, analyzing the nuclear extract, and found that the treatment with Bicalutamide alone stimulated Maspin production, but the treatment with Bicalutamide plus NCPA induced a very large amount and nuclear accumulation of Maspin (Fig. 6B). Finally, we analyzed cell cycle progression and apoptosis/necrosis induction finding that the pretreatment with Bicalutamide and treatment with NCPA induced the 
increase of cell number in subG1 stage $65.4 \%$ Bicalutamide alone at $72 \mathrm{~h}, 61 \%$ at $24 \mathrm{~h}, 79.8 \%$ at $48 \mathrm{~h}$ and $79.5 \%$ at $72 \mathrm{~h}$ after NCPA treatment (Fig. 6C). The increase of cell number in subG1 in Bicalutamide plus NCPA at $72 \mathrm{~h}$ was statistically significant compared to the apoptosis rate in Bicalutamide alone at $72 \mathrm{~h}(\mathrm{p}<0.05)$. The apoptosis/necrosis assay showed that Bicalutamide treatment induced early apoptosis, $7.8 \%$ at $72 \mathrm{~h}$, whereas Bicalutamide plus NCPA induced an increased percentage of cells in early apoptosis, $4.1 \%, 15.5 \%$ and $20.2 \%$ at $24 \mathrm{~h}$, $48 \mathrm{~h}$ and $72 \mathrm{~h}$, respectively (Bicalutamide plus NCPA vs Bicalutamide alone at $72 \mathrm{~h}$ was statistically significant, $\mathrm{p}<0.01$ ). Same result was obtained for late apoptosis, Bicalutamide alone $4.6 \%$ at $72 \mathrm{~h}$, Bicalutamide plus NCPA $5.1 \%, 28.6 \%$ and $51.3 \%$ at $24 \mathrm{~h}, 48 \mathrm{~h}$ and $72 \mathrm{~h}$, respectively (Bicalutamide plus NCPA vs Bicalutamide alone at $72 \mathrm{~h}$ was statistically significant, $\mathrm{p}<0.001$ ) (Fig. 6D).

\section{Discussion}

Maspin, a non-inhibitory member of the serine protease inhibitor superfamily, Serpin B, has been characterized as a class II tumor suppressor gene in several cancer types, such as breast, lung, epithelial and prostate cancer $[6,8,22,23]$, due to its ability to inhibit cell invasiveness and angiogenesis, and to increase apoptosis [4], therefore inhibiting metastasis [24]. These Maspin features are of utmost interest in medical field suggesting that Maspin complies a role as a therapeutic agent for several forms of malignancies [4,25]. In normal prostate epithelial cells, Maspin is highly expressed and is found localized in cytoplasm, nucleus, secretory vesicles and occasionally at cell surface $[25,26]$, whereas in prostate cancer cell lines, PC3, LNCaP and DU145, its expression is almost completely suppressed [27]. Moreover, Maspin has been found highly expressed in tumor specimens from patients treated with neoadjuvant androgen ablation therapy [11]. On the other hand, patients with Maspin expressing prostate cancer had a significantly longer survival rate $[25,28]$.

Previously, in our laboratory, we studied glucosamine (GlcN) and a glucosamine-derivative, NAPA, which showed a good anti-inflammatory activity inhibiting p38 and JNK kinases, and in turn interfere with AP-1 pathway $[29,30]$. GlcN and mainly NAPA were also able to inhibit NF-KB pathway, particularly by inhibiting IKK $\alpha$ migration into the nucleus and its kinase activity [16]. IKKa belongs to IKK complex, which controls the activation of NF- $\mathrm{KB}$ pathway, and considering that recently, the nuclear role of IKKa has been associated to cancer progression through repression of Maspin expression [14], we decided to study whether our molecules could be able to interfere with Maspin production. In order to obtain a more effective IKK $\alpha$ inhibitor, we synthesized a new glucosamine-derivative, 2-(N-Carbobenzyloxy)Lphenylalanylamido-2-deoxy- $\beta$-D-glucose (NCPA), which revealed to be very effective in inhibiting IKKa and to stimulate Maspin production in osteosarcoma cell lines, 143B and Saos-2 [17]. We decided to analyze the effectiveness of NCPA in two human prostate cancer cell lines, PC3 and LNCaP, which have been extensively used as models to study the progression of this type of tumor. LNCaP cell line is considered an early stage of prostate cancer, whose development is based on androgensensitive cell growth [31,32], and the progression has been shown to be based on an androgen receptor (AR)-independent cell growth [33]. On the other hand, PC3 cell line is considered representative of advanced disease, due to its source of origin and to androgen-insensitive features [34,35]. The AR is not expressed in PC3, and this cell line is more aggressive compared to LNCaP. Moreover, the androgen-insensitivity, due to lack of AR expression, is associated to more aggressive tumor phenotype in some patients. Considering the differences between LNCaP and PC3 we decided to analyze the effects of NCPA on both cell lines, focusing the attention on the ability to stimulate Maspin production. The first difference we found was that NCPA was able to inhibit cell viability in PC3 and not in LNCaP. Moreover, our molecule stimulated the production of Maspin only in PC3, which was mainly localized in the nuclear fraction. This finding is noteworthy, considering that several authors described this localization as essential for its tumor suppressor activity [7,8,36,37]. Goulet et al. demonstrated that nuclear Maspin is physically associated to target gene promoters, suggesting that its metastasis suppressor functions could involve, at least in part, this kind of mechanism [36].

The tumor-suppressing and anti-metastatic activities of Maspin have been also attributed to its ability to inhibit cell cycle progression and to stimulate apoptosis of tumor cells [25,26,38]. Therefore, we analyzed the effects of NCPA on PC3 and LNCaP cell lines, with regard to those processes, finding that the compound caused a cell cycle progression blockage in PC3, whereas cell cycle progression of treated LNCaP cells was not affected. Cyclin D1 is considered a key regulator of the progression of cell cycle through G1 phase and its overexpression is also been related to the evolution of androgen-independent prostate cancer [39]. Analyzing the expression level of Cyclin D1 both in PC3 and LNCaP, we found that Cyclin D1 was up-regulated in PC3 and not in LNCaP and that the NCPA treatment decreased the expression level in PC3. Our data are in agreement with those of Lee et al., who found that the arrest in G1 phase was related to decrease of Cyclin D1 and upregulation of Maspin in Oral Squamous Cell Carcinoma Cells [40]. The overexpression of Cyclin D1 has been associated to gene amplification mainly in hormone-insensitive and metastatic prostate cancer samples, whereas, the amplification rate is very low in early stage prostate cancer samples [19]. According to these findings, we found that CCND1 gene is largely amplified in PC3 cell line, representing an advanced and hormone-insensitive prostate cancer, and is barely amplified in LNCaP, representing an early stage and hormone-sensitive prostate cancer. Interestingly, NCPA was effective mainly in PC3 cells decreasing the cell number with amplified CCND1 from $40 \%$ to $4 \%$. In LNCaP, the percentage of cells with CCND1 gene amplification was only $12 \%$ and was lowered to $7 \%$ after treatment, which was not statistically significant. Turner et al. found that the amplification of some common oncogenes, among them CCND1, can be attributed to extra chromosomal DNA (ecDNA) [21]. Anyway, they found that CCDN1 amplification in PC3 cell line is not due to ecDNA, but resides on chromosomal loci [21]. We can speculate that NCPA could be effective mainly in cell with CCND1 chromosomal loci amplification. The data on CCND1 amplification are in agreement with analysis of tubulin filaments, performed by immunofluorescence, showing a large amount of mitotic spindles in untreated PC3 compared to NCPA-treated PC3. Moreover, the number of mitotic spindles was lower in untreated LNCaP compared to untreated PC3 (Supplementary Fig. 1).

Finally, we analyzed the ability of NCPA to induce apoptosis in PC3 cells, finding that progressively the percentage of both early and late apoptotic cells was increased, with the higher amount at $72 \mathrm{~h}$. This is in agreement with the increase of nuclear Maspin at $24 \mathrm{~h}$, suggesting that the nuclear activity of this protein gives rise to the production of molecules involved in apoptosis processes. Noteworthy, the amount of Maspin was slightly increased again at $72 \mathrm{~h}$ suggesting that this inhibitor could support the apoptotic process.

Interestingly, Coulson-Thomas et al. demonstrated that, in the early phases of prostate cancer development, the tumor cells are surrounded by Lumican, a Small Leucine-rich proteoglycan (SLRP), which inhibits tumor progression and invasion [41]. During cancer progression, the cancer cells increase the production of MMPs degrading the deposited stromal lumican. Moreover, Villermoz et al. showed that the overexpression of lumican in a mouse cancer model induced the decrease of Cyclin D1 production, increased apoptosis rate and in turn significantly decreased subcutaneous tumor formation in vivo [42]. Previously, we demonstrated that GlcN and glucosamine-derivative NAPA, were able to stimulate extracellular matrix components, among them also the SLRP lumican and collagens $[43,44]$. Considering that NCPA is a glucosamine-derivative, very similar to NAPA, we can hypothesize that also NCPA induces lumican production, strengthening the effects on cell cycle and apoptosis that we observed. Moreover, Dzinic et al. showed that Maspin is involved in the production of extracellular matrix in 
prostate cancer cell line [45].

A hormone negative regulatory element is present in the promoter region of Maspin gene [10].

Taking into account this finding, Zou et al. [11] demonstrated that LNCaP cultured in androgen-depleted medium exhibit induction of Maspin expression. We treated LNCaP with AR inhibitor Bicalutamide and with Bicalutamide plus NCPA finding that our molecule, in this condition, was able to induce the expression of Maspin also in LNCaP cells and in turn was able to promote the apoptosis. In particular, Bicalutamide plus NCPA induced a higher production of Maspin compared to Bicalutamide alone, and consequently also the apoptosis rate was higher in Bicalutamide plus NCPA compared to Bicalutamide alone. Considering that Bicalutamide barely induced apoptosis and NCPA was not effective at all on LNCaP cells, whereas the contemporary administration of Bicalutamide plus NCPA induced 51,3\% late apoptosis rate, we suggest that the combination of two molecules results in a synergistic effect on cell line. This evidence highlights the possibility of a use of NCPA as a chemosensitizing agent.

In conclusion, we demonstrated that our molecule glucosaminederivative, NCPA, stimulated Maspin production both in PC3 and in LNCaP cell line pre-treated with a hormone inhibitor, inducing the apoptosis. The increase of autologous Maspin, would be a desirable therapeutic strategy, considering that the delivery of recombinant Maspin by adenoviral construct or liposomal DNA complexes is accompanied with safety and efficacy issues $[22,46]$.

\section{Author contributions}

Conception and design of the study: Cocchiola, Scotto d'Abusco.

Acquisition of data: Cocchiola, Lopreiato, Guazzo, De Santi.

Analysis and interpretation of data: Cocchiola, Lopreiato, Eufemi, Scandurra, Scotto d'Abusco.

Drafting of article: Cocchiola, Scotto d'Abusco.

All authors read and approved the final manuscript.

\section{Conflicts of interest}

The Authors declare that they have not competing interests. RS and ASd have a patent (\# 102016000030071) on NCPA molecule.

\section{Acknowledgments}

A special thanks to Dr L. Mosca for helpful discussion.

This research was partially supported by grant "Progetto di Facoltà 2017”, prot. N. RM11715C7E7AC924.

\section{Transparency document}

Transparency document related to this article can be found online at https://doi.org/10.1016/j.cbi.2019.01.014.

\section{Appendix A. Supplementary data}

Supplementary data to this article can be found online at https:// doi.org/10.1016/j.cbi.2019.01.014.

\section{References}

[1] A.M. DeMarzo, W.G. Nelson, W.B. Isaacs, J.I. Epstein, Pathological and molecular aspects of prostate cancer, Lancet 361 (2003) 955-964.

[2] E. Nevedomskaya, S.J.- Baumgart, B. Haendler, Recent advances in prostate cancer treatment and drug discovery, Int. J. Mol. Sci. 19 (2018) pii: E1359.

[3] M. Kaarbø, T.I. Klokk, F. Saatcioglu, Androgen signaling and its interactions with other signaling pathways in prostate cancer, Bioessays 29 (2007) 1227-1238.

[4] T.M. Bodenstine, R.E. Seftor, Z. Khalkhali-Ellis, E.A. Seftor, P.A. Pemberton, M.J. Hendrix, Maspin: molecular mechanisms and therapeutic implications, Cancer Metastasis Rev. 31 (2012) 529-551.

[5] S. Sheng, J. Carey, E.A. Seftor, L. Dias, M.J. Hendrix, R. Sager, Maspin acts at the cell membrane to inhibit invasion and motility of mammary and prostatic cancer cells, Proc. Natl. Acad. Sci. U.S.A. 93 (1996) 11669-11674.

[6] C.H. Streuli, Maspin is a tumour suppressor that inhibits breast cancer tumour metastasis in vivo, Breast Cancer Res. 4 (2002) 137-140.

[7] M. Machowska, K. Wachowicz, M. Sopel, R. Rzepecki, Nuclear location of tumor suppressor protein maspin inhibits proliferation of breast cancer cells without affecting proliferation of normal epithelial cells, BMC Canc. 14 (2014) 142.

[8] F. Lonardo, X. Li, F. Siddiq, R. Singh, M. Al-Abbadi, H.I. Pass, S. Sheng, Maspin nuclear localization is linked to favorable morphological features in pulmonary adenocarcinoma, Lung Canc. 51 (2006) 31-39.

[9] F. Gou, S. Kang, P. Zhou, L. Guo, L. Ma, J. Hou, Maspin expression is regulated by the non-canonical NF- $\mathrm{kB}$ subunit in androgen-insensitive prostate cancer cell lines, Mol. Immunol. 49 (2011) 8-17.

[10] M. Zhang, D. Magit, R. Sager, Expression of maspin in prostate cells is regulated by a positive ets element and a negative hormonal responsive element site recognized by androgen receptor, Proc. Natl. Acad. Sci. U.S.A. 94 (1997) 5673-5678.

[11] Z. Zou, W. Zhang, D. Youn, M.G. Gleave, P. Rennie, T. Connell, R. Connelly, J. Moul, S. Srivastava, I. Sesterhenn, Maspin expression profile in human prostate cancer (CaP) and in vitro induction of Maspin expression by androgen ablation, Clin. Canc. Res. 8 (2002) 1172-1177.

[12] S. Vallabhapurapu, M. Karin, Regulation and function of NF- $\mathrm{kB}$ transcription factors in the immune system, Annu. Rev. Immunol. 27 (2009) 693-733.

[13] M. Karin, NF-kappaB as a critical link between inflammation and cancer, Cold Spring Harb Perspect Biol 1 (2009) a000141.

[14] J.L. Luo, W. Tan, J.M. Ricono, O. Korchynskyi, M. Zhang, S.L. Gonias, D.A. Cheresh, M. Karin, Nuclear cytokine-activated IKKa controls prostate cancer metastasis by repressing Maspin, Nature 446 (2007) 690-694.

[15] C. Giordano, C. Gallina, V. Consalvi, R. Scandurra, Synthesis and properties of Dglucosamine N-peptidyl derivatives as substrate analog inhibitors of papain and cathepsin B, Eur. J. Med. Chem. 26 (1991) 753-762.

[16] A. Scotto d'Abusco, L. Politi, C. Giordano, R. Scandurra, A peptidyl-glucosamine derivative affects IKKa kinase activity in human chondrocytes, Arthritis Res. Ther. 12 (2010) R18.

[17] M. Leopizzi, R. Cocchiola, E. Milanetti, D. Raimondo, L. Politi, C. Giordano, R. Scandurra, A. Scotto d'Abusco, IKKa inibition by a glucosamine derivative enhances maspin expression in osteosarcoma cell line, Chem. Biol. Interact. 262 (2017) 19-28.

[18] T.D. Schmittgen, K.J. Livak, Analyzing real-time PCR data by the comparative C(T) method, Nat. Protoc. 3 (2008) 1101-1108.

[19] L. Bubendorf, J. Kononen, P. Koivisto, P. Schraml, H. Moch, T.C. Gasser, N. Willi, M.J. Mihatsch, G. Sauter, O.P. Kallioniemi, Survey of gene amplifications during prostate cancer progression by high-throughout fluorescence in situ hybridization on tissue microarrays, Cancer Res. 59 (1999) 803-806.

[20] H.S. Kim, H. Lee, S.J. Shin, S.H. Beom, M. Jung, S. Bae, E.Y. Lee, K.H. Park, Y.Y. Choi, T. Son, H.I. Kim, J.H. Cheong, W.J. Hyung, J.C. Park, S.K. Shin, S.K. Lee, Y.C. Lee, W.S. Koom, J.S. Lim, H.C. Chung, S.H. Noh, S.Y. Rha, H. Kim, S. Paik, Complementary utility of targeted next-generation sequencing and immunohistochemistry panels as a screening platform to select targeted therapy for advanced gastric cancer, Oncotarget 8 (2017) 38389-38398.

[21] K.M. Turner, V. Deshpande, D. Beyter, T. Koga, J. Rusert, C. Lee, B. Li, K. Arden, B. Ren, D.A. Nathanson, H.I. Kornblum, M.D. Taylor, S. Kaushal, W.K. Cavenee, R. Wechsler-Reya, F.B. Furnari, S.R. Vandenberg, P.N. Rao, G.M. Wahl, V. Bafna, P.S. Mischel, Extrachromosomal oncogene amplification drives tumour evolution and genetic heterogeneity, Nature 543 (2017) 122-125.

[22] Z. Zou, A. Anisowicz, M.J. Hendrix, A. Thor, M. Neveu, S. Sheng, K. Rafidi, E.A. Seftor, R. Sager, Maspin, a serpin with tumor-suppressing activity in human mammary epithelial cells, Science 263 (1994) 526-529.

[23] D.C. Hall, T.L. Johnson-Pais, B. Grubbs, R. Bernal, R.J. Leach, S.S. Padalecki, Maspin reduces prostate cancer metastasis to bone, Urol. Oncol. 26 (2008) 652-658.

[24] Shankar, E.; Candamo, M.; MacLennan, G.T.; Gupta, S. Maspin Expression and its Metastasis suppressing function in prostate cancer. \%22Prostate Cancer - LeadingEdge Diagnostic Procedures and Treatments\%22 Book edited by Ravinder Mohan, https://doi.org/10.5772/64336.

[25] R. Berardi, F. Morgese, A. Onofri, P. Mazzanti, M. Pistelli, Z. Ballatore, A. Savini, M. De Lisa, M. Caramanti, S. Rinaldi, S. Pagliaretta, M. Santoni, C. Pierantoni, S. Cascinu, Role of maspin in cancer, Clin. Transl. Med. 2 (2013) 8.

[26] X. Yu, S.L. Harris, A.J. Levine, The regulation of exosome secretion: a novel function of the p53 protein, Cancer Res. 66 (2006) 4795-4801.

[27] M.M. Bernardo, Y. Meng, J. Lockett, G. Dyson, A. Dombkowski, A. Kaplun, X. Li, S. Yin, S. Dzinic, M. Olive, I. Dean, D. Krass, K. Moin, R.D. Bonfil, M. Cher, W. Sakr, $\mathrm{S}$. Sheng, Maspin reprograms the gene expression profile of prostate carcinoma cells for differentiation, Genes Cancer 2 (2011) 1009-1922.

[28] S. Machtens, J. Serth, C. Bokemeyer, W.V. Bathke, A. Minssen, C. Kollmannsberger, J. Hartmann, R. Knüchel, M. Kondo, U. Jonas, M. Kuczyk, Expression of the p53 and Maspin protein in primary prostate cancer: correlation with clinical features, Int. J. Canc. 95 (2001) 337-342.

[29] A. Scotto d'Abusco, V. Calamia, C. Cicione, B. Grigolo, L. Politi, R. Scandurra, Glucosamine affects intracellular signalling through inhibition of mitogen-activated protein kinase phosphorylation in human chondrocytes, Arthritis Res. Ther. 9 (2007) R104.

[30] A. Scotto d'Abusco, C. Cicione, V. Calamia, R. Negri, C. Giordano, B. Grigolo, L. Politi, R. Scandurra, Glucosamine and its N-acetyl-phenylalanine derivative prevent TNF-alpha-induced transcriptional activation in human chondrocytes, Clin. Exp. Rheumatol. 25 (2007) 847-852.

[31] E.H. Nunlist, I. Dozmorov, Y. Tang, R. Cowan, M. Centola, H.K. Lin, Partitioning of 
$5 \alpha$-dihydrotestosterone and $5 \alpha$-androstane- $3 \alpha, 17 \beta$-diol activated pathways for stimulating human prostate cancer LNCaP cell proliferation, J. Steroid Biochem. Mol. Biol. 91 (2004) 157-170.

[32] M.G. Dozmorov, R.E. Hurst, D.J. Culkin, B.P. Kropp, M.B. Frank, J. Osban, T.M. Penning, H.K. Lin, Unique patterns of molecular profiling between human prostate cancer LNCaP and PC-3 cells, Prostate 69 (2009) 1077-1090.

[33] H.K. Lin, Y.C. Hu, L. Yang, S. Altuwaijri, Y.T. Chen, H.Y. Kang, C. Chang, Suppression versus induction of androgen receptor functions by the phosphatidylinositol 3-kinase/Akt pathway in prostate cancer LNCaP cells with different passage numbers, J. Biol. Chem. 278 (2003) 50902-50907.

[34] S. Tai, Y. Sun, J.M. Squires, H. Zhang, W.K. Oh, C.Z. Liang, J. Huang, PC3 is a cell line characteristic of prostatic small cell carcinoma, Prostate 71 (2011) 1668-1679.

[35] R. Cocchiola, D. Romaniello, C. Grillo, F. Altieri, M. Liberti, F.M. Magliocca, S. Chichiarelli, I. Marrocco, G. Borgoni, G. Perugia, M. Eufemi, Analysis of STAT3 post-translational modifications (PTMs) in human prostate cancer with different Gleason Score, Oncotarget 8 (2017) 42560-42570.

[36] B. Goulet, W. Kennette, A. Ablack, C.O. Postenka, M.N. Hague, J.S. Mymryk, A.B. Tuck, V. Giguère, A.F. Chambers, J.D. Lewis, Nuclear localization of maspin is essential for its inhibition of tumor growth and metastasis, Lab. Invest. 91 (2011) $1181-1187$.

[37] L.A. Solomon, A.R. Munkarah, V.L. Schimp, M.H. Arabi, R.T. Morris, H. Nassar, R. Ali-Fehmi, Maspin expression and localization impact on angiogenesis and prognosis in ovarian cancer, Gynecol. Oncol. 101 (2006) 385-389.

[38] J.S. Schaefer, M. Zhang, Role of maspin in tumor metastasis and angiogenesis, Curr. Mol. Med. 3 (2003) 653-658.

[39] M. Drobnjak, I. Osman, H.I. Scher, M. Fazzari, C. Cordon-Cardo, Overexpression of cyclin D1 is associated with metastatic prostate cancer to bone, Clin. Canc. Res, 6 (2000) 1891-1895.
[40] J.C. Lee, K.C. Chiang, T.H. Feng, Y.J. Chen, S.T. Chuang, K.H. Tsui, L.C. Chung, H.H. Juang, The iron chelator, Dp44mT, effectively inhibits human oral squamous cell carcinoma cell growth in vitro and in vivo, Int. J. Mol. Sci. 17 (2016) pii: E1435.

[41] V.J. Coulson-Thomas, Y.M. Coulson-Thomas, T.F. Gesteira, C.A. Andrade de Paula, C.R. Carneiro, V. Ortiz, L. Toma, W.W. Kao, H.B. Nader, Lumican expression, localization and antitumor activity in prostate cancer, Exp. Cell Res. 319 (2013) 967-981.

[42] B. Vuillermoz, A. Khoruzhenko, M.F. D'Onofrio, L. Ramont, L. Venteo, C. Perreau, F. Antonicelli, F.X. Maquart, Y. Wegrowski, The small leucine-rich proteoglycan lumican inhibits melanoma progression, Exp. Cell Res. 296 (2004) 294-306.

[43] D. Stoppoloni, L. Politi, M. Leopizzi, S. Gaetani, R. Guazzo, S. Basciani, O. Moreschini, M. De Santi, R. Scandurra, A. Scotto d'Abusco, Effect of glucosamine and its peptidyl-derivative on the production of extracellular matrix components by human primary chondrocytes, Osteoarthritis Cartilage 23 (2015) 103-113.

[44] F. Veronesi, G. Giavaresi, M. Maglio, A. Scotto d'Abusco, L. Politi, R. Scandurra, E. Olivotto, B. Grigolo, R.M. Borzì, M. Fini, Chondroprotective activity of N-acetyl phenylalanine glucosamine derivative on knee joint structure and inflammation in a murine model of osteoarthritis, Osteoarthritis Cartilage 25 (2017) 589-599.

[45] S.H. Dzinic, K. Chen, A. Thakur, A. Kaplun, R.D. Bonfil, X. Li, J. Liu, M.M. Bernardo, A. Saliganan, J.B. Back, H. Yano, D.L. Schalk, E.N. Tomaszewski, A.S. Beydoun, G. Dyson, A. Mujagic, D. Krass, I. Dean, Q.S. Mi, E. Heath, W. Sakr, L.G. Lum, S. Sheng, Maspin expression in prostate tumor elicits host anti-tumor immunity, Oncotarget 5 (2014) 11225-11236.

[46] H.Y. Shi, R. Liang, N.S. Templeton, M. Zhang, Inhibition of breast tumor progression by systemic delivery of the maspin gene in a syngeneic tumor model, Mol. Ther. 5 (2002) 755-761. 